\title{
Mitochondrial Release of Cytochrome $c$ Corresponds to the Selective Vulnerability of Hippocampal CA1 Neurons in Rats after Transient Global Cerebral Ischemia
}

\author{
Taku Sugawara, Miki Fujimura, Yuiko Morita-Fujimura, Makoto Kawase, and Pak H. Chan \\ Departments of Neurosurgery and Neurology and Neurological Sciences and Program in Neurosciences, Stanford \\ University School of Medicine, Palo Alto, California 94304
}

Release of cytochrome $c$ from mitochondria to the cytosol is a critical step in apoptotic cell death after focal cerebral ischemia. The relationship among cytochrome $c$ release, selective vulnerability, and delayed death of hippocampal CA1 neurons after transient global ischemia was examined. Global ischemia was induced by 10 min of bilateral common carotid artery occlusion and hypotension in rats. Cytosolic expression of cytochrome $c$ was evaluated by immunohistochemistry and Western blotting. Apoptosis after global ischemia was also characterized by terminal deoxynucleotidyl transferase-mediated uridine 5'triphosphate-biotin nick end-labeling (TUNEL) staining and DNA gel electrophoresis. Immunohistochemistry showed cytosolic cytochrome c-positive cells exclusively in the CA1 subregion of the hippocampus as early as $2 \mathrm{hr}$ after ischemia. Double fluorescent immunostaining confirmed that CA1 neurons and a small number of astrocytes expressed cytochrome $c$. Western blot analysis revealed a band $(15 \mathrm{kDa})$ of cytochrome $c$ in the cytosolic fraction and a corresponding decrease in the mitochondrial fraction. A significant number of TUNEL-positive cells appeared only in the CA1 pyramidal cell layer of the hippocampus, and DNA gel electrophoresis showed a significant amount of DNA fragmentation 3-5 d after ischemia. Our data provide the first evidence that cytochrome $c$ was released to the cytosol from mitochondria in CA1 neurons after global ischemia and that the release preceded DNA fragmentation. These findings suggest cytochrome $c$ involvement in the delayed death of hippocampal CA1 neurons in rats after transient global ischemia.

Key words: transient global cerebral ischemia; cytochrome c; apoptosis; caspase; hippocampal CA1 neuron; astrocyte
Mitochondria are assumed to be involved in apoptosis by releasing cytochrome $\mathrm{c}$ from their intermembrane space to the cytoplasm. If deoxy-ATP (dATP) is present, cytochrome $c$ binds to the CED-4 homolog Apaf-1, and subsequently, Apaf-1 binds to procaspase-9, resulting in activation of caspase-9, which has been shown to be an initiator of the cytochrome $c$-dependent caspase cascade (Li et al., 1997b; Kuida et al., 1998; Yoshida et al., 1998). Activated caspase-9 directly cleaves procaspase-3, and active caspase-3 (CPP32) triggers activation of additional caspases and leads to apoptosis (Liu et al., 1996; Slee et al., 1999).

The transient global ischemia model has been used to analyze selective vulnerability in the hippocampal CA1 subregion. Neuronal death in the CA1 subregion after global ischemia has been shown to occur in a delayed manner (Kirino, 1982), and recent studies have demonstrated that these neuronal deaths are in part caused by apoptosis (MacManus et al., 1993; Nitatori et al., 1995). CPP32, an important caspase in the cytochrome $c$-dependent caspase cascade, is overexpressed in the CA1 subregion after transient global ischemia, and administration of a CPP32 inhibitor reduces apoptotic cell death (Chen et al., 1998). These findings strongly suggest the involvement of cytochrome $c$ in

\footnotetext{
Received June 4, 1999; revised Aug. 26, 1999; accepted Sept. 14, 1999.

This study was supported by National Institutes of Health Grants NS14543, NS25372, NS36147, NS38653, and NO1 NS82386. P.H.C. is a recipient of the Jacob Javits Neuroscience Investigator Award. We thank Bernard Calagui, Liza Reola, and Jane O. Kim for technical assistance and Cheryl Christensen for editorial assistance.

Correspondence should be addressed to Dr. Pak H. Chan, Neurosurgical Laboratories, Stanford University, 701B Welch Road, 148, Palo Alto, CA 94304. E-mail: phchan@leland.stanford.edu.

Copyright (C) 1999 Society for Neuroscience 0270-6474/99/190001-06\$05.00/0
}

delayed death of CA1 neurons after transient global ischemia. However, recent morphological data question the role of apoptosis in this phenomenon (Colbourne et al., 1999). For this reason, the present study is undertaken to investigate the possible role of cytochrome $c$ release from mitochondria in vulnerable neurons as a possible apoptotic mechanism after global ischemia.

\section{MATERIALS AND METHODS}

Global cerebral ischemia. Ten minutes of transient global ischemia was induced in male Sprague Dawley rats (275-325 gm) by bilateral common carotid artery occlusion and bleeding to lower the mean arterial blood pressure to $30-35 \mathrm{mmHg}$, using the method originally described by Smith et al. (1984) with some modifications (Chan et al., 1998). The rectal temperature was controlled at $37.0 \pm 0.5^{\circ} \mathrm{C}$ during surgery with a feedback-regulated heating pad.

Immunohistochemistry of cytochrome c. Animals were anesthetized and perfused with $4 \%$ formaldehyde in PBS 2, 6, and $12 \mathrm{hr}$ and 1,2,3, and $5 \mathrm{~d}$ after ischemia and reperfusion. Brains were sectioned coronally, 50 $\mu \mathrm{m}$ in thickness, on a vibratome and incubated with a monoclonal anti-cytochrome $c$ antibody (PharMingen, San Diego, CA) at a dilution

This article is published in The Journal of Neuroscience, Rapid Communications Section, which publishes brief, peerreviewed papers online, not in print. Rapid Communications are posted online approximately one month earlier than they would appear if printed. They are listed in the Table of Contents of the next open issue of JNeurosci. Cite this article as: JNeurosci, 1999, 19:RC39(1-6). The publication date is the date of posting online at www.jneurosci.org.

http://www.jneurosci.org/cgi/content/full/3674 
of 1:500, followed by procedures previously described (Fujimura et al., 1998). Then the sections were counterstained with methyl green for nuclear staining. Consecutive sections were stained with cresyl violet for histological assessment of neuronal damage.

Fluorescent double labeling with cytochrome $\mathrm{c}$ and neuron-specific nuclear protein immunohistochemistry. Fixed sections were incubated with a monoclonal anti-vertebrate neuron-specific nuclear protein $(\mathrm{NeuN})$ antibody (Chemicon, Temecula, CA) at a dilution of 1:100, and with Texas Red-conjugated horse anti-mouse IgG antibody. Subsequently, the sections were incubated in an anti-cytochrome $c$ antibody at a dilution of 1:500 and with biotinylated horse anti-mouse antibody and fluoresceinavidin (Vector Laboratories, Burlingame, CA). Fluorescence of Texas Red was observed at excitation of $510 \mathrm{~nm}$ and emission of $>580 \mathrm{~nm}$. Fluorescence of fluorescein was also observed at excitation of $495 \mathrm{~nm}$ and emission of $>515 \mathrm{~nm}$.

Fluorescent double labeling with cytochrome $\mathrm{c}$ and glial fibrillary acidic protein immunohistochemistry. Fixed sections were first processed with an anti-cytochrome $c$ antibody and fluorescein-avidin and then incubated in a polyclonal anti-glial fibrillary acidic protein (GFAP) antibody (Santa Cruz Biotechnology, Santa Cruz, CA) at a dilution of 1:500, and Texas Red-conjugated anti-goat antibody. Fluorescence was assessed as described above.

Western blot analysis. Protein extraction of both the mitochondrial and cytosolic fractions was performed 6 and $12 \mathrm{hr}$ and 1 and $3 \mathrm{~d}$ after ischemia as described (Fujimura et al., 1998). Proteins were separated by SDS-PAGE on a 10-20\% Tris-glycine gel (Novex, San Diego, CA) and transferred to a polyvinylidene difluoride membrane (Novex). The primary antibodies were either a 1:1000 dilution of cytochrome $c$ monoclonal (PharMingen) or $1 \mu \mathrm{g} / \mathrm{ml}$ of 20E8C12 cytochrome oxidase subunit IV monoclonal (Molecular Probes, Eugene, OR). Western blots were performed with horseradish peroxidase-conjugated anti-mouse IgG (Boehringer Mannheim, Indianapolis, IN) using the chemiluminescence method as previously described (Fujimura et al., 1999). After the film was scanned with a GS-700 imaging densitometer (Bio-Rad, Hercules, CA), a quantitative analysis was performed using Multi-Analyst software (Bio-Rad). Western blot analysis of $\beta$-actin was also performed.

In situ labeling of DNA fragmentation. The experimental animals were killed at 1, 3, and $5 \mathrm{~d}$ after $10 \mathrm{~min}$ of global ischemia and reperfusion. Brains were rapidly frozen and sectioned coronally, $25 \mu \mathrm{m}$ in thickness, on a cryostat. The sections at the level of the hippocampus were stained using an in situ technique [terminal deoxynucleotidyl transferasemediated uridine 5'-triphosphate-biotin nick end labeling (TUNEL) reaction] to detect the DNA free $3^{\prime}-\mathrm{OH}$ ends as described (Fujimura et al., 1998). The sections were counterstained with methyl green.

$D N A$ gel electrophoresis. Animals were killed 1, 3, and 5 d after 10 min of global ischemia and reperfusion. Forty to $60 \mathrm{mg}$ wet weight of tissue were taken from the hippocampal CA1 subregion, and DNA bands were visualized as described (Fujimura et al., 1999; Kawase et al., 1999).

Quantification and statistical analysis. TUNEL-positive cells were counted, and the ratio of the TUNEL-positive cells to the total number of cells in the CA1 pyramidal cell layer was calculated. The damaged area of the CA1 subregion was calculated as previously described (Chan et al., 1998). Cytosolic cytochrome $c$-positive large cells in the CA1 subregion were quantified with a light microscope by locating a $50 \times 5 \mathrm{~mm}$ grid at high magnification $(400 \times)$ approximately at the center of the CA1 subregion. The quantitative analyses were evaluated using factorial ANOVA among each group. Significance among groups was assigned at $p<0.05$.

\section{RESULTS}

\section{Histological analysis of hippocampal injury}

Histological changes in the CA1 pyramidal cell layer first appeared $2 \mathrm{~d}$ after ischemia. Some cells showed an ischemic change, such as triangle-shaped shrunken nuclei or a condensed nucleus with visible nucleoli. Three days after ischemia, the majority of the CA1 pyramidal cells underwent ischemic change. These histological findings were compatible with our previous reports (Chan et al., 1998; Kawase et al., 1999).

\section{Immunohistochemistry demonstrated cytosolic cytochrome $c$ expression}

Fifty-eight rats were immunohistochemically examined. Diff use cytosolic immunoreactive large cells appeared in the CA1 pyra- midal cell layer but not in other subregions of the hippocampus as early as $2 \mathrm{hr}$ after ischemia (Fig. $1 B-F$, arrows). They were sometimes accompanied by one long, stem-like structure protruding from the cytosol (Fig. 1B,C, arrowheads), resembling an axon. In the sham-operated rats, cytochrome $c$-immunoreactive cells were virtually not seen in the hippocampus (Fig. $1 A$ ). Two days or later after ischemia, a characteristic pattern of cytosolic cytochrome $c$ staining was barely observed, and the entire CA1 pyramidal cell layer, including the intercellular space, became immunoreactive (Fig. $1 G$ ). In the stratum radiatum of the CA1 subregion, small numbers of cytochrome $c$-positive fine processes appeared $1 \mathrm{~d}$ after ischemia (Fig. $1 H$ ). These processes were sometimes combined and formed star-like shapes resembling astrocytes, and then they disappeared $5 \mathrm{~d}$ after ischemia.

\section{Fluorescent double labeling confirmed subpopulations of cytochrome $c$-positive cells}

The nucleus and cytoplasm of almost all large cells in the CA1 pyramidal cell layer were NeuN-positive, indicating that those cells were neurons (Fig. 1I). The cytochrome $c$-positive cells (Fig. $1 J)$ were confirmed to be neurons by overlapping cytochrome $c$ and NeuN images of the same high-power field (Fig. $1 \mathrm{~K}$ ). Cytochrome $c$-positive fine processes with and without cell bodies in the stratum radiatum (Fig. $1 L$ ) were all GFAP-positive (Fig. 1M); however, the number of cytochrome $c$-positive astrocytes accounted for a minority of GFAP-positive astrocytes.

\section{Western blot analysis demonstrating the release of cytochrome $\boldsymbol{c}$ from mitochondria}

Cytochrome $c$ immunoreactivity was evident as a single band of molecular mass of $15 \mathrm{kDa}$ in the cytosolic fraction of the hippocampal CA1 subregion $6 \mathrm{hr}$ to $3 \mathrm{~d}$ after global ischemia. However, it was barely detected in the normal CA1 subregion (Fig. $2 A$ ). Contrarily, a consistent amount of $\beta$-actin immunoreactivity is seen in Figure $2 A$, bottom panel, suggesting that the amount of the loaded protein was consistent. A significant amount of mitochondrial cytochrome $c$ was detected in the controls and decreased after ischemia, corresponding to a marked increase in the cytosolic fraction (Fig. 2B). Cytochrome oxidase was strongly expressed in the mitochondrial fraction and did not decrease after ischemia, but virtually no immunoreactivity was seen in the cytosolic fraction in both the control and ischemic CA1 subregions (Fig. $2 B$ ). Statistical analysis ( $n=4$ each) confirmed the significant increase $(p<0.05)$ of cytochrome $c$ in the cytosolic fraction $1 \mathrm{~d}$ after ischemia [optical density $(\mathrm{OD})=$ $0.479 \pm 0.168]$ compared with normal CA1 subregions $(\mathrm{OD}=$ $0.167 \pm 0.051)$. The decrease of cytochrome $c$ in the mitochondrial fraction $1 \mathrm{~d}$ after ischemia (OD $=0.155 \pm 0.043$ ) was also significant $(p<0.05)$ compared with normal CA1 subregions $(0.323 \pm 0.130)$.

\section{TUNEL staining and the time course of TUNEL-positive cells, damaged CA1 area, and cytochrome c-positive neurons}

In control rats or $1 \mathrm{~d}$ after ischemia, there were almost no TUNEL-positive cells in the CA1 subregion (Fig. $3 A$ ). A significant number of positive cells were observed 3 and $5 \mathrm{~d}$ after ischemia (Fig. 3B). Some of them showed characteristic appearances, such as shrunken, condensed nuclei and apoptotic bodies. However, others showed lightly stained, large, and swollen nuclei. We excluded the cells with the latter features from the TUNELpositive cells, because they might have contained necrotic cells. The time course of the TUNEL-positive neurons is shown in 

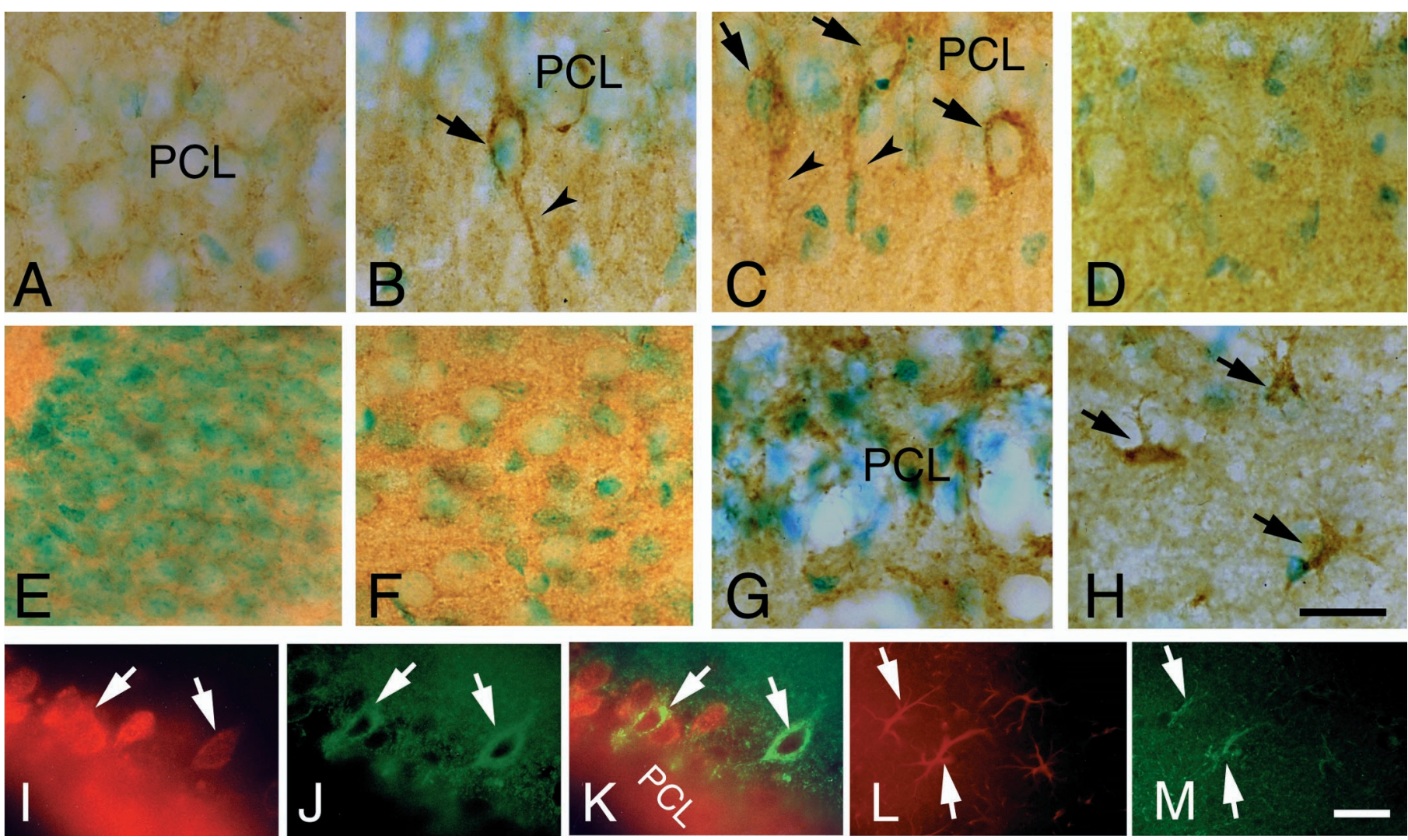

Figure 1. Representative photomicrographs of cytochrome $c$ immunostaining. Results were confirmed by at least three independent studies for each time point. $A-H$, Cytochrome $c$ immunostaining with methyl green counterstaining of the rat hippocampus. No specific staining was seen in the CA1 subregion of sham-operated controls $(A)$. Characteristic diffuse cytosolic immunoreactivity $(B, C$, arrows $)$ was observed in the CA1 pyramidal cell layer $6 \mathrm{hr}(B)$ and $12 \mathrm{hr}(C)$ after ischemia. The cells with cytochrome $c$-positive cytosol were often accompanied by axon-like long processes $(B$, $C$, arrowheads). Cytosolic immunoreactivity was not seen in the CA3 subregion $(D)$, the dentate gyrus $(E)$, or the cortex $(F)$. Two days after ischemia, the intercellular space became immunoreactive in the pyramidal cell layer $(G)$. However, some stellate-shaped cells were cytochrome $c$-positive in the stratum radiatum $(H) . I-M$, Double fluorescent immunostaining with cytochrome $c$ and NeuN $1 \mathrm{~d}$ after ischemia $(I-K)$ and with cytochrome $c$ and GFAP $2 \mathrm{~d}$ after ischemia $(L, M)$ in the hippocampal CA1 subregion. Most of the cells in the pyramidal cell layer were NeuN-positive $(I)$. The cytosolic cytochrome $c$-immunoreactive cells (J, arrows) were also positive for NeuN. K, Overlapped image from the same field. Some of the GFAP-positive astrocytes $(L)$ in the stratum radiatum were also positive for cytochrome $c$ (M, arrows). PCL, Pyramidal cell layer. Scale bar, $20 \mu \mathrm{m}$.

Figure $3 C$, which correlated well with that of histological damage (Fig. 3D). A significant number of cytosolic cytochrome $c$-positive neurons appeared $2 \mathrm{hr}$ after ischemia and reached a peak at $12 \mathrm{hr}$ (Fig. 3E). Only the cells with diffuse cytosolic staining were considered to be cytochrome $c$-positive. However, quantification was not performed at $2 \mathrm{~d}$ or later, because cytosolic cytochrome $c$ staining was not clearly distinguished from diff use intercellular immunoreactivity.

\section{DNA laddering was detected by DNA gel electrophoresis}

To confirm the nucleosomal DNA fragmentation, which is characteristic of apoptosis, we analyzed DNA from the hippocampal CA1 subregion. DNA laddering was absent in both the control tissue and tissue $1 \mathrm{~d}$ after ischemia. A significant amount of DNA laddering was detected in the hippocampal CA1 subregion at $3 \mathrm{~d}$ and was increased at $5 \mathrm{~d}$ (Fig. 4).

\section{DISCUSSION}

\section{Cytosolic expression of cytochrome $c$ in CA1 neurons}

Immunohistochemistry showed that a significant number of cytochrome $c$-positive cells with a characteristic cytosolic staining pattern appeared in the hippocampal CA1 subregion as early as 2 hr after ischemia. We determined that these cells were neurons for the following reasons. First, the size of the nuclei was obviously larger than that of other cell populations such as astrocytes or oligodendrocytes. Second, some of the cells had cytochrome $c$-positive, single stem-like structures, which resembled axons. Third, these cells were always positive for NeuN staining, which reacts with neuronal nuclei and their cell bodies throughout the adult nervous system (Mullen et al., 1992). Two days after ischemia or later, cytosolic cytochrome $c$-immunoreactive CA1 neurons were barely observed. This could be partly caused by shrinkage of the cytosol of neurons undergoing apoptosis and by difficulty in distinguishing cytosolic staining from diff use intercellular staining. Because cytochrome $c$ is known as a watersoluble protein, the diff use intercellular immunoreactivity is presumably derived from dispersed cytochrome $c$ from disrupted neurons, which underwent either necrosis or apoptosis.

\section{Subcellular distribution of cytochrome $c$ demonstrated by Western blotting}

Our results provide evidence that cytochrome $c$ is released from mitochondria to the cytosol in CA1 cells after transient global ischemia. The subcellular distribution of cytochrome $c$ was confirmed by Western blot analysis. A significant amount of mitochondrial cytochrome $c$ was detected in the normal hippocampal CA1 subregion and was decreased $6 \mathrm{hr}$ to $3 \mathrm{~d}$ after ischemia. 


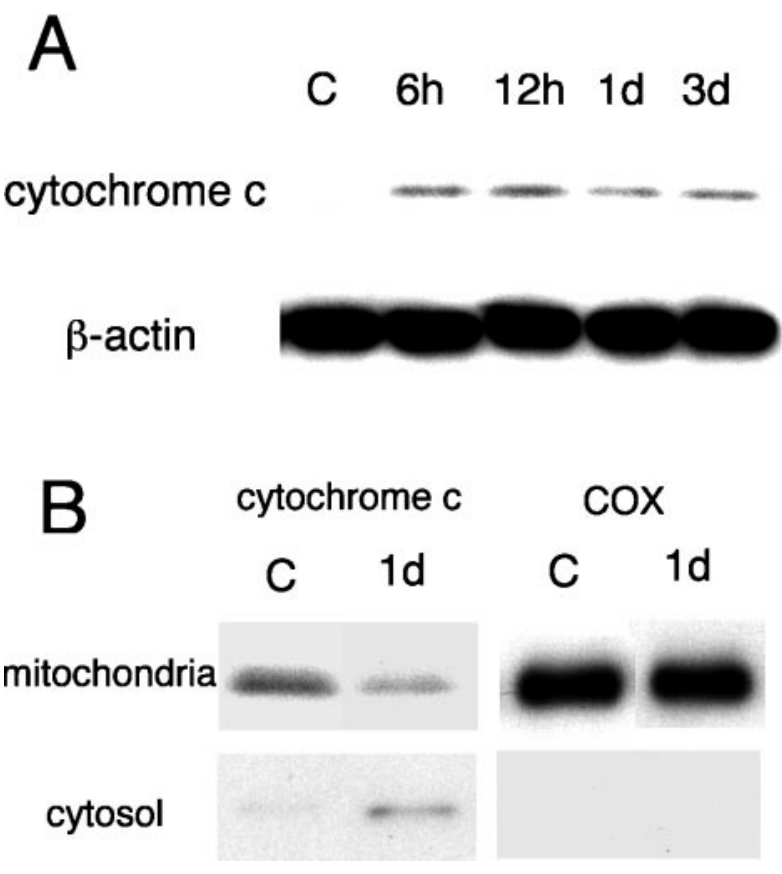

Figure 2. Western blot analysis of cytochrome $c$ and cytochrome oxidase in rat hippocampal CA1 subregion. Cytochrome $c$ immunoreactivity is evident as a single band of molecular mass $(15 \mathrm{kDa})$ in the cytosolic fraction $6 \mathrm{hr}$ to $3 \mathrm{~d}$ after ischemia (A, lanes 2-5), but not in the control CA1 tissue $(A$, lane 1$)$. On the other hand, a consistent amount of $\beta$-actin immunoreactivity is shown in $A$, bottom panel. Cytochrome $c$ from the mitochondrial fraction decreased $1 \mathrm{~d}$ after ischemia compared with the control, corresponding to an increase in the cytosolic fraction $(B$, left panels). Cytochrome oxidase was strongly expressed in the mitochondrial fraction and did not decrease after ischemia, but virtually no immunoreactivity was seen in the cytosolic fraction in both the control and ischemic CA1 subregions ( $B$, right panels). The results shown are representative of three independent studies. $C$, Normal control animals; $C O X$, cytochrome oxidase.

Correspondingly, cytosolic cytochrome $c$ showed a marked increase at the same time points, whereas cytochrome oxidase showed no obvious alteration in subcellular distribution after ischemia. The increase in cytosolic cytochrome $c$ could derive from other sources, such as ischemia-induced upregulation or impaired protein import. Cytochrome $c$ is known to be synthesized in the endoplasmic reticulum and ribosome; however, those organelles were excluded by ultracentrifuge. We cannot exclude the possibility that cytosolic cytochrome $c$ is partly derived from impaired protein import, and further investigation is necessary to clarify this point. From the findings of immunohistochemistry and Western blotting, we believe that increased cytosolic cytochrome $c$ is substantially derived from the mitochondria of CA1 neurons.

\section{Neuronal apoptosis after transient global ischemia}

The transient global ischemia model has been used to analyze selective vulnerability in the hippocampal CA1 subregion. Some apoptotic features have been shown by TUNEL staining (MacManus et al., 1993; Nitatori et al., 1995; Chan et al., 1998), and internucleosomal DNA fragmentation has been detected by a DNA laddering pattern (Heron et al., 1993; Kawase et al., 1999). Because TUNEL staining simply indicates DNA damage, and its specificity for apoptosis is still controversial, we used this staining as an indication of DNA damage in cells and applied other morphological criteria (Fig. 3) to exclude the possible presence of
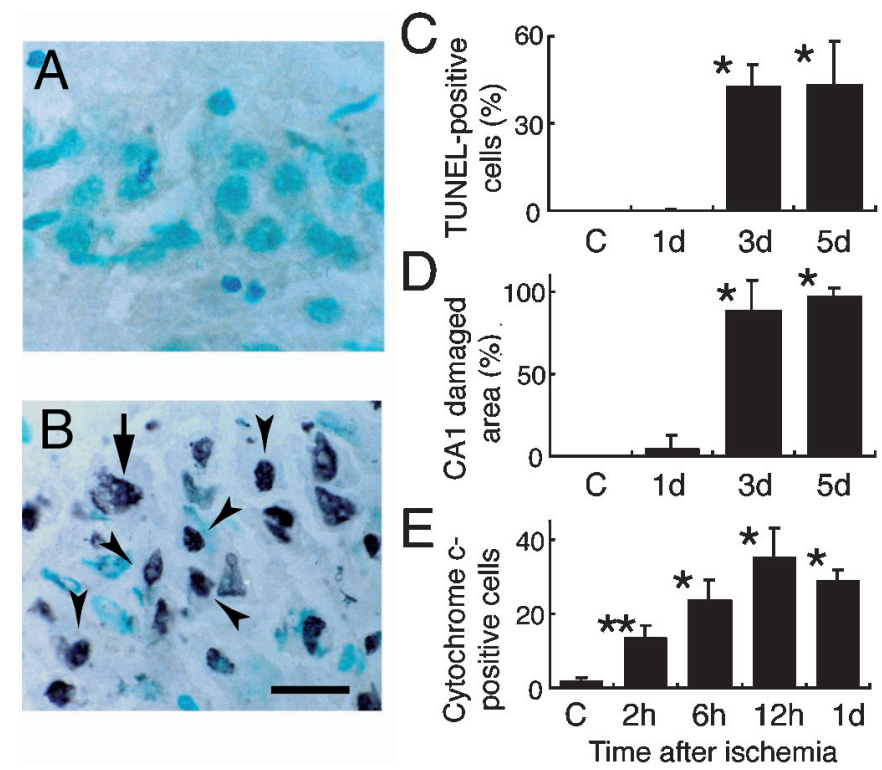

Figure 3. Representative photomicrographs of TUNEL staining counterstained with methyl green $(A, B)$, and quantitative analyses of TUNEL-positive cells $(C)$, the damaged area $(D)$, and cytochrome $c$-positive cells in the rat hippocampal CA1 subregion $(E)$. TUNEL staining $1 \mathrm{~d}$ after ischemia showed virtually no positive cells $(A)$; however, most of the cells became positive $3 \mathrm{~d}$ after ischemia $(B)$. Some cells had shrunken, darkly stained nuclei and apoptotic bodies (arrowheads). Others had lightly stained, large, and swollen nuclei (arrow). The cells with the latter features were not counted as TUNEL-positive cells. Quantitative analyses showed a marked increase in TUNEL-positive cells $(C)$ and the damaged CA1 area $(D) 3 \mathrm{~d}$ after ischemia. The number of cytochrome $c$-positive cells significantly increased at $2 \mathrm{hr}$ and peaked 12 $\mathrm{hr}$ after ischemia $(E)$. $C$, Untreated control animals. All values shown are mean $\pm \operatorname{SD}(n=4) .{ }^{*} p<0.01 ;{ }^{*} p<0.05$ from control level.

necrotic cells. We have shown that $<1 \%$ of cells were TUNELpositive $1 \mathrm{~d}$ after ischemia. However, $>40 \%$ became positive $3 \mathrm{~d}$ after ischemia in the hippocampal CA1 subregion. In contrast, histologically damaged cells accounted for nearly $90 \%$ at $3 \mathrm{~d}$ and almost $100 \% 5 \mathrm{~d}$ after ischemia. These data indicate that delayed neuronal death after transient global ischemia in the hippocampal CA1 subregion is caused by both necrosis and apoptosis. In the present study, a significant amount of DNA laddering was detected at 3 and $5 \mathrm{~d}$. However, we cannot exclude the possibility that this DNA laddering is from other subpopulations, such as astrocytes or oligodendrocytes, because they can undergo apoptosis after brain injury. Further studies using double staining of NeuN and TUNEL are necessary to address this issue.

Recently, Colbourne et al. (1999) reported on electron microscopic observations against apoptosis, such as early organelle swelling, disaggregation of polyribosomes, and cell and nuclear membrane breaks in CA1 neurons after global ischemia in gerbils. However, the protective effects of caspase inhibitors on delayed neuronal death (Goto et al., 1990; Chen et al., 1998) strongly suggest that the biochemical caspase cascade plays a major role in neuronal cell death after global ischemia. Furthermore, expression of caspase- 9 and CPP32 in the hippocampal CA1 subregion (Chen et al., 1998; Ni et al., 1998; Krajewski et al., 1999) before DNA fragmentation may argue for the biochemical evidence of apoptosis.

\section{Cytochrome $\boldsymbol{c}$ involvement in apoptosis}

Many studies have shown that cytochrome $c$ plays a key role in apoptosis. In a cell-free system, this protein activates CPP32, a 


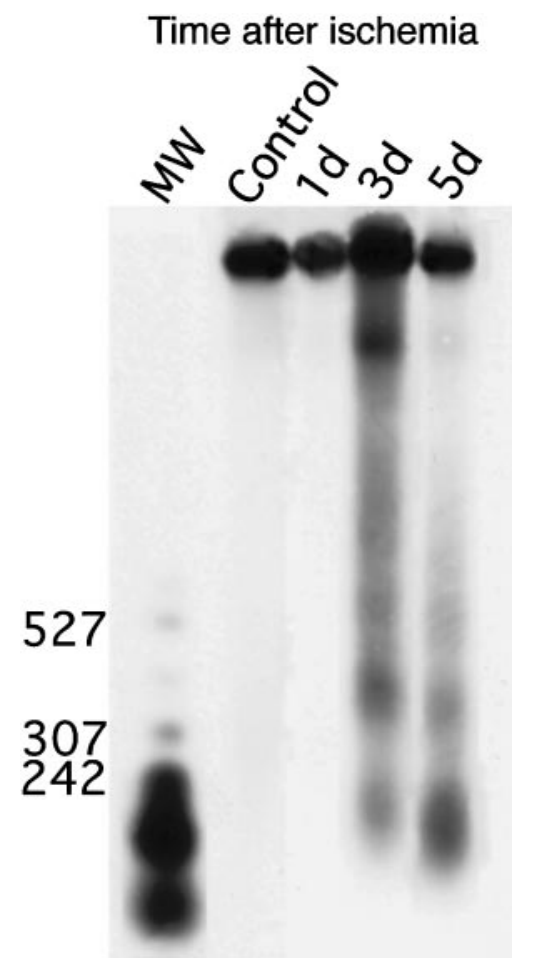

Figure 4. Genomic DNA agarose gel electrophoresis. No DNA laddering is observed in the rat hippocampal CA1 subregion of the normal control brain (lane 1) or $1 \mathrm{~d}$ after ischemia (lane 2). DNA laddering was detected in the hippocampal CA1 subregion 3 and $5 \mathrm{~d}$ after ischemia (lanes 3,4). The results are representative of two animals for each time point. $M W$, Molecular weight.

cysteine protease of the interleukin- $1 \beta$-converting enzyme family, which triggers apoptosis (Liu et al., 1996). Microinjection of cytochrome $c$ also induces cell-specific apoptosis ( $\mathrm{Li}$ et al., 1997a). Furthermore, in a cell-free system and in intact cells, the expression of $\mathrm{Bcl}-2$ or $\mathrm{Bcl}-\mathrm{X}_{\mathrm{L}}$ blocks translocation of cytochrome $c$ from mitochondria to the cytosol and thereby inhibits CPP32 activation and apoptosis (Kluck et al., 1997; Yang et al., 1997). More recently, Uchino et al. (1998) reported that cyclosporin A ameliorates the histological damage in the hippocampal CA1 subregion after global ischemia. Because this drug prevents the mitochondrial permeability transition and subsequent DNA fragmentation of the hippocampus after hypoglycemia (FerrandDrake et al., 1999), it would be of great interest to evaluate the cytochrome $c$ expression after administration of cyclosporin A in the global ischemia model.

Once cytochrome $c$ is released from mitochondria in the early stages of apoptosis, it interacts with the CED-4 homolog Apaf-1, and dATP, leading to the activation of caspase-9 (Li et al., 1997b; Zou et al., 1997; Kuida et al., 1998; Yoshida et al., 1998). Caspase-9, which is presumably an initiator of the cytochrome $c$-dependent caspase cascade, then activates CPP32, followed by caspase-2, -6, -8, and -10 activation downstream (Slee et al., 1999). After global ischemia in rats, CPP32 mRNA and protein were predominantly increased in degenerating CA1 pyramidal neurons as early as $8 \mathrm{hr}$ after transient global ischemia (Chen et al., 1998). And we demonstrated cytosolic cytochrome $c$ expression exclusively in CA1 neurons as early as $2 \mathrm{hr}$ after ischemia, preceding CPP32 activation. With regard to the order in which apoptosisinducing factors are activated in the rat hippocampal CA1 subregion, these data are compatible with the latest concept of the cytochrome $c$-dependent caspase cascade. Furthermore, exclusive spatial distribution of cytochrome c, CPP32, and CPP32 mRNA in CA1 neurons also supports this concept and may help explain the selective vulnerability.

\section{Cytochrome $c$ expression in astrocytes}

In the stratum radiatum of the CA1 subregion, cytochrome $c$-positive fine processes of astrocytes appeared 1-3 d after ischemia. However, we did not observe TUNEL-positive cells in the stratum radiatum, where a majority of GFAP-positive astrocytes existed, until $5 \mathrm{~d}$ after ischemia. Apoptosis of astrocytes is known to occur in the developing brain and also in the pathological adult brain, including the ischemic brain (Matsuyama et al., 1994). Interestingly, recent in vitro studies have shown that both embryonic and mature astrocytes express a significant level of CD95 (Fas/APO-1) receptors on their surface (Becher et al., 1998; Saas et al., 1999); however, only mature astrocytes are likely to undergo CD95-mediated apoptosis (Saas et al., 1999), not cytochrome $c$-mediated apoptosis. Delayed expression of cytochrome $c$ in astrocytes may be caused by CD95-mediated activation of the caspase cascade, because the activation of this cascade also promotes cytochrome $c$ release (Kuwana et al., 1998). However, CD95 expression, ligation, and subsequent apoptosis have to be characterized to address this issue. Because too little is known about apoptosis of astrocytes after global ischemia, we are not able to exclude the possibility that they undergo apoptosis later. TUNEL staining and DNA gel electrophoresis at later time points are necessary to clarify this point.

\section{Conclusion}

Our studies have demonstrated that cytochrome $c$ was released from the mitochondria to the cytosol in CA1 neurons and preceded the induction of DNA-fragmented cells after transient global ischemia in rats. These results imply that cytochrome $c$ release might play a role in delayed CA1 neuronal death.

\section{REFERENCES}

Becher B, D'Souza SD, Troutt AB, Antel JP (1998) Fas expression on human fetal astrocytes without susceptibility to fas-mediated cytotoxicity. Neuroscience 84:627-634.

Chan PH, Kawase M, Murakami K, Chen SF, Li Y, Calagui B, Reola L, Carlson E, Epstein CJ (1998) Overexpression of SOD1 in transgenic rats protects vulnerable neurons against ischemic damage after global cerebral ischemia and reperfusion. J Neurosci 18:8292-8299.

Chen J, Nagayama T, Jin K, Stetler RA, Zhu RL, Graham SH, Simon RP (1998) Induction of caspase-3-like protease may mediate delayed neuronal death in the hippocampus after transient cerebral ischemia. J Neurosci 18:4914-4928.

Colbourne F, Sutherland GR, Auer RN (1999) Electron microscopic evidence against apoptosis as the mechanism of neuronal death in global ischemia. J Neurosci 19:4200-4210.

Ferrand-Drake M, Friberg H, Wieloch T (1999) Mitochondrial permeability transition induced DNA-fragmentation in the rat hippocampus following hypoglycemia. Neuroscience 90:1325-1338.

Fujimura M, Morita-Fujimura Y, Murakami K, Kawase M, Chan PH (1998) Cytosolic redistribution of cytochrome $c$ after transient focal cerebral ischemia in rats. J Cereb Blood Flow Metab 18:1239-1247.

Fujimura M, Morita-Fujimura Y, Kawase M, Copin J-C, Calagui B, Epstein CJ, Chan PH (1999) Manganese superoxide dismutase mediates the early release of mitochondrial cytochrome $c$ and subsequent DNA fragmentation after permanent focal cerebral ischemia in mice. J Neurosci 19:3414-3422.

Goto K, Ishige A, Sekiguchi K, Iizuka S, Sugimoto A, Yuzurihara M, Aburada M, Hosoya E, Kogure K (1990) Effects of cycloheximide on delayed neuronal death in rat hippocampus. Brain Res 534:299-302.

Heron A, Pollard H, Dessi F, Moreau J, Lasbennes F, Ben-Ari Y, Charriaut-Marlangue C (1993) Regional variability in DNA fragmentation after global ischemia evidenced by combined histological and gel 
electrophoresis observations in the rat brain. $\mathrm{J}$ Neurochem 61:1973-1976.

Kawase M, Fujimura M, Morita-Fujimura Y, Chan PH (1999) Reduction of apurinic/apyrimidinic endonuclease expression after transient global cerebral ischemia in rats. Implication of the failure of DNA repair in neuronal apoptosis. Stroke 30:441-449.

Kirino T (1982) Delayed neuronal death in the gerbil hippocampus following ischemia. Brain Res 239:57-69.

Kluck RM, Bossy-Wetzel E, Green DR, Newmeyer DD (1997) The release of cytochrome $c$ from mitochondria: a primary site for $\mathrm{Bcl}-2$ regulation of apoptosis. Science 275:1132-1136.

Krajewski S, Krajewska M, Ellerby LM, Welsh K, Xie Z, Deveraux QL, Salvesen GS, Bredesen DE, Rosenthal RE, Fiskum G, Reed JC (1999) Release of caspase-9 from mitochondria during neuronal apoptosis and cerebral ischemia. Proc Natl Acad Sci USA 96:5752-5757.

Kuida K, Haydar TF, Kuan CY, Gu Y, Taya C, Karasuyama H, Su MS, Rakic P, Flavell RA (1998) Reduced apoptosis and cytochrome $c$-mediated caspase activation in mice lacking caspase 9. Cell 94:325-337.

Kuwana T, Smith JJ, Muzio M, Dixit V, Newmeyer DD, Kornbluth S (1998) Apoptosis induction by caspase-8 is amplified through the mitochondrial release of cytochrome $c$. J Biol Chem 273:16589-16594.

Li F, Srinivasan A, Wang Y, Armstrong RC, Tomaselli KJ, Fritz LC (1997a) Cell-specific induction of apoptosis by microinjection of cytochrome $c$. Bcl-xL has activity independent of cytochrome $c$ release. J Biol Chem 272:30299-30305.

Li P, Nijhawan D, Budihardjo I, Srinivasula SM, Ahmad M, Alnemri ES, Wang X (1997b) Cytochrome $c$ and dATP-dependent formation of Apaf-1/caspase-9 complex initiates an apoptotic protease cascade. Cell 91:479-489.

Liu X, Kim CN, Yang J, Jemmerson R, Wang X (1996) Induction of apoptotic program in cell-free extracts: requirement for dATP and cytochrome $c$. Cell 86:147-157.

MacManus JP, Buchan AM, Hill IE, Rasquinha I, Preston E (1993) Global ischemia can cause DNA fragmentation indicative of apoptosis in rat brain. Neurosci Lett 164:89-92.

Matsuyama T, Hata R, Tagaya M, Yamamoto Y, Nakajima T, Furuyama
J, Wanaka A, Sugita M (1994) Fas antigen mRNA induction in postischemic murine brain. Brain Res 657:342-346.

Mullen RJ, Buck CR, Smith AM (1992) NeuN, a neuronal specific nuclear protein in vertebrates. Development 116:201-211.

Ni B, Wu X, Su Y, Stephenson D, Smalstig EB, Clemens J, Paul SM (1998) Transient global forebrain ischemia induces a prolonged expression of the caspase- $3 \mathrm{mRNA}$ in rat hippocampal CA1 pyramidal neurons. J Cereb Blood Flow Metab 18:248-256.

Nitatori T, Sato N, Waguri S, Karasawa Y, Araki H, Shibanai K, Kominami E, Uchiyama Y (1995) Delayed neuronal death in the CA1 pyramidal cell layer of the gerbil hippocampus following transient ischemia is apoptosis. J Neurosci 15:1001-1011.

Saas P, Boucraut J, Quiquerez AL, Schnuriger V, Perrin G, Desplat-Jego S, Bernard D, Walker PR, Dietrich PY (1999) CD95 (Fas/Apo-1) as a receptor governing astrocyte apoptotic or inflammatory responses: a key role in brain inflammation? J Immunol 162:2326-2333.

Slee EA, Harte MT, Kluck RM, Wolf BB, Casiano CA, Newmeyer DD, Wang HG, Reed JC, Nicholson DW, Alnemri ES, Green DR, Martin SJ (1999) Ordering the cytochrome $c$-initiated caspase cascade: hierarchical activation of caspases-2, -3, -6, -7, -8, and -10 in a caspase-9dependent manner. J Cell Biol 144:281-292.

Smith ML, Bendek G, Dahlgren N, Rosen I, Wieloch T, Siesjö BK (1984) Models for studying long-term recovery following forebrain ischemia in the rat. 2. A 2-vessel occlusion model. Acta Neurol Scand 69:385-401.

Uchino H, Elmer E, Uchino K, Li PA, He QP, Smith ML, Siesjö BK (1998) Amelioration by cyclosporin A of brain damage in transient forebrain ischemia in the rat. Brain Res 812:216-226.

Yang J, Liu X, Bhalla K, Kim CN, Ibrado AM, Cai J, Peng T-I, Jones DP, Wang X (1997) Prevention of apoptosis by Bcl-2: release of cytochrome $c$ from mitochondria blocked. Science 275:1129-1132.

Yoshida H, Kong YY, Yoshida R, Elia AJ, Hakem A, Hakem R, Penninger JM, Mak TW (1998) Apaf1 is required for mitochondrial pathways of apoptosis and brain development. Cell 94:739-750.

Zou H, Henzel WJ, Liu X, Lutschg A, Wang X (1997) Apaf-1, a human protein homologous to $C$. elegans CED-4: participates in cytochrome $c$-dependent activation of caspase-3. Cell 90:405-413. 